\title{
Evaluasi Ketahanan Beberapa Galur Kacang Bambara (Vigna subterranea L. Verdc) Madura Terhadap Kekeringan
}

\author{
(Resistance Evaluation Some Strains of Bambara Groundnut (Vigna subterranea L. Verdc) Madura to Drought) \\ Ahmad Syaiful Umam ${ }^{1}$, Kaswan Badami², dan A. Sidqi Zaed Z.M² \\ ${ }^{1}$ Student of Study Program of Agrotechnology, Faculty of Agriculture, University of Trunojoyo Madura \\ ${ }^{2}$ Lecturer, Lecture of Agrotechnology, Faculty of Agricultur, University of Trunojoyo Madura \\ *Email korespondensi: syaifulumam1@gmail.com
}

Diterima 01 Februari 2019/Disetujui 20 Februari 2019

\begin{abstract}
Bambara Groundnut is known as one of the plants that are resistant to drought. This plant originates from Africa which was later developed in Indonesia. This research aimed to know the resistance of some strains of the bambara groundnut to drought as well as the required minimum water needs of plants to keep growing and producing well. This study used a Randomized Complete Design (RAL) Factorial with three replicates. Consists of 4 strains $(G 1, G 2, G 3, G 4)$ and 4 degrees of watering $(P 1, P 2, P 3, P 4)$ so there are 16 treatment combinations. Treatment of strains gives the effect on parameter results (flowering age, number of pods, root length, number of seeds and seed weight), while watering affects all parameters of observation. Watering rate of $100 \%$ field capacity $(P 1)$ best exert influence on each observation parameters, where as the best interaction is shown in the G4P4 parameter on each observation. Minimum water needs bambara groundnut crops i.e. at level $(P 2)$.
\end{abstract}

Keywords: Bambara Groundnut, Strain, Drought

\begin{abstract}
ABSTRAK
Tanaman Kacang Bambara dikenal sebagai salah satu tanaman yang tahan terhadap kekeringan. Tanaman ini berasal dari Afrika yang kemudian dikembangkan di Indonesia. Penelitian ini bertujuan untuk mengetahui ketahanan beberapa galur kacang bambara terhadap kekeringan serta kebutuhan air minimum yang dibutuhkan tanaman untuk tetap tumbuh dan berproduksi dengan baik. Penelitian ini menggunakan Rancangan Acak Lengkap (RAL) Faktorial dengan 3 kali ulangan. Terdiri atas 4 galur $(G 1, G 2, G 3, G 4)$ dan 4 taraf penyiraman $(P 1, P 2, P 3, P 4)$ sehingga terdapat 16 kombinasi perlakuan. Perlakuan galur memberikan pengaruh terhadap parameter hasil (umur berbunga, jumlah polong, panjang akar, jumlah biji dan berat biji), sedangkan penyiraman mempengaruhi semua parameter pengamatan. Taraf penyiraman $100 \%$ kapasitas lapang (P1) memberikan pengaruh terbaik pada setiap parameter pengamatan, sedangkan interaksi terbaik ditunjukkan pada G4P4 pada setiap parameter pengamatan. Kebutuhan air minimum tanaman kacang bambara yaitu pada taraf penyiraman $75 \%$ Kapasitas Lapang (P2).
\end{abstract}

Kata kunci: Kacang Bambara, Galur, Kekeringan

\section{PENDAHULUAN}

Kacang Bambara (Vigna subterranea L. Verdc) atau kacang bogor berasal dari Afrika yang berkembang di kawasan Amerika, Asia dan Australia. Tanaman ini dikembangkan di daerah sub Sahara Afrika, terutama pada daerah semi kering. Di Asia, Kacang Bambara telah dibudidayakan di India, Indonesia, Malaysia, Philipina dan Thailand.

Galur Kacang Bambara Indonesia yang ditemukan di Indonesia sangat banyak. Kuswanto (2012) menyebutkan bahwa telah ditemukan 50 galur Kacang Bambara Indonesia berasal dari Jawa Barat dan Jawa Timur. Kacang Bambara di Indonesia telah lama beradaptasi dengan baik di wilayah
Bogor dan bagian timur Jawa Barat, sehingga lebih dikenal sebagai Kacang Bogor.

Iklim di Indonesia yang terdiri dari musim hujan dan musim kemarau memberikan keuntungan untuk bercocok tanam. Pada kedua musim tersebut berbagai macam tanaman yang memiliki syarat tumbuh tertentu dapat tumbuh dengan subur. Menurut Jusuf (2012), pemanasan global berdampak pada perubahan iklim di dunia menjadi tidak stabil. Apabila pemanasan global terus bertambah setiap tahunnya dapat menimbulkan dampak yang sangat besar terhadap percepatan ancaman yang seperti badai siklon tropis, air pasang dan banjir, kenaikan temperatur ekstrim, tsunami, kekeringan dan El Nino yang dapat menimbulkan risiko bencana pada sistem ekologis. 
Madura dikenal dengan daerah yang memiliki tingkat kekeringan tinggi. Tingkat kekeringan lahan di Madura disebabkan curah hujan yang rendah serta intensitas penyinaran matahari yang sangat tinggi, sehingga tanaman yang tumbuh di Madura sering mengalami cekaman air. Menurut Hendrati (2012), Di pulau Madura curah hujan hasil pengamatan pada Balai Pengelolaan Daerah Aliran Sungai Jawa Timur selama 10 tahun (1995-2006) menunjukkan curah hujan yang relatif rendah di empat kabupaten yaitu Bangkalan, Sampang, Pamekasan dan Sumenep yang berturut-turut menunjukkan curah hujan 1.411, 1.120, 790 dan 928 mm/tahun. Data curah hujan yang dikumpulkan dari berbagai lokasi tersebut menunjukkan curah hujan yang umumnya rendah ( $<1.500 \mathrm{~mm} / \mathrm{tahun})$. Keadaan seperti ini sering menjadi masalah besar bagi sebagian besar petani Madura untuk mencari komoditas yang sesuai ditanam pada lahan kering yang mereka miliki.

Kacang Bambara memiliki potensi yang baik di Indonesia, namun masih belum diketahui seberapa besar kemampuan galur Kacang Bambara untuk dapat tumbuh pada kondisi cekaman kekeringan. Cekaman kekeringan merupakan suatu kondisi dimana air dalam tanah tidak mencukupi untuk mendukung pertumbuhan tanaman secara optimal.

Tanaman yang terkena cekaman kekeringan akan berpengaruh terhadap pertumbuhan. Harsono, et al., (2003) menambahkan bahwa genotip tanaman kacang tanah yang tahan kering pada kondisi tercekam kekeringan mempunyai transpirasi lebih rendah, fotosintesis lebih tinggi, menggunakan air lebih efisien dan mampu memberikan hasil polong lebih tinggi dibanding genotip rentan kekeringan. Perlu diketahui sejauh mana kemampuan galur-galur Kacang Bambara lokal Madura tahan terhadap cekaman kekeringan dengan melakukan penelitian mengenai ketahanan galur-galur Kacang Bambara Madura terhadap kekeringan.

Dari latar belakang di atas, dapat disimpulkan bahwa dengan tingkat kekeringan lahan di Madura perlu dilakukan penelitian cekaman air yang dapat direkomendasikan kepada petani bahwa Kacang Bambara Madura menjadi salah satu komoditas yang dapat ditanam pada kondisi kering. Permasalahan yang ada pada masyarakat terkait sulitnya komoditas yang mampu bertahan dengan cekaman yang tinggi dapat diatasi dengan penelitian-penelitian beberapa jenis tanaman yang mampu tumbuh dan berproduksi tinggi pada lahan kering Madura.

\section{METODE PENELITIAN}

Penelitian ini dilakukan di Greenhouse Agroteknologi Fakultas Pertanian Universitas Trunojoyo Madura pada bulan Februari 2016 - Juni 2016. Alat yang digunakan diantaranya polybag, cangkul, sekop, ember, gelasukur, meteran, penggaris, timbangan, alat tulis, kertas dan label. Bahan yang digunakan dalam penelitian ini adalah benih 3 galur Kacang Bambara Madura dan 1 galur Kacang
Bambara Lokal Indonesia, media tanah mediteran, air, pupuk Urea, SP36, KCl, kompos dan pestisida. Penelitian ini menggunakan Rancangan Acak Lengkap (RAL) Faktorial dengan tiga kali ulangan.

Faktor 1: Taraf Penyiraman (P) dengan 4 taraf, yaitu :

1. (P1) taraf penyiraman $100 \% \mathrm{KL}$

2. (P2) taraf penyiraman $75 \% \mathrm{KL}$

3. (P3) taraf penyiraman $50 \% \mathrm{KL}$

4. (P4) taraf penyiraman $25 \% \mathrm{KL}$.

Faktor 2: Penggunaan Galur Kacang Bambara (G) dengan 4 taraf, yaitu :

1. Galur Madura $1(\mathrm{G} 1)$

2. Galur Madura $2(\mathrm{G} 2)$

3. Galur Madura 3 (G3)

4. Galur Lokal Indonesia (G4)

Sehingga terdapat 16 kombinasi perlakuan untuk semua parameter pengamatan. Teknik pelaksanaan penelitian terdiri dari: persiapan media tanam, pengukuran kapasitas lapang, penanaman, pemeliharaan, pemupukan, pemberian perlakuan, pemanenan. Parameter pengamatan yang dilakukan antara lain tinggi tanaman, jumlah daun, umur berbunga, panjang akar, jumlah polong, jumlah biji dan berat biji.

\section{HASIL DAN PEMBAHASAN}

\section{Karakter Pertumbuhan}

\section{Tinggi Tanaman}

Hasil analisis menunjukkan bahwa P3 memiliki rerata tertinggi $5,84 \mathrm{~cm}$ dan $\mathrm{P} 4$ memiliki rerata terendah yaitu 4,94 cm. sedangkan P1 dan P2 menunjukkan nilai tidak berbeda nyata, selisih rerata keduanya yaitu $5,72 \mathrm{~cm}$ dan 5,10 cm. (Tabel 1).

\section{Jumlah daun}

Hasil analisis menunjukkan bahwa taraf P1 memberikan nilai tertinggi dengan rerata 18,28 dibandingkan taraf P2, P3 dan P4. Hal ini Menunjukkan bahwa faktor penyiraman memberikan pengaruh signifikan terhadap jumlah daun kacang bambara. (Tabel 2).

\section{Panjang Akar}

Panjang akar terpanjang ditunjukkan pada G3 dengan rerata 13,02 cm, sedangkan akar terpendek terjadi pada G4 dengan rerata $11,85 \mathrm{~cm}$. Rerata panjang akar terpanjang terdapat pada taraf P1 dengan rerata $14,55 \mathrm{~cm}$, kemudian disusul oleh taraf P2 dengan rerata $13,30 \mathrm{~cm}$, sedangkan panjang akar terendah terdapat pada taraf $\mathrm{P} 4$ dengan rerata $9,98 \mathrm{~cm}$. Pada interaksi G3 P1 yang memiliki panjang akar terpanjang dengan rerata $15,17 \mathrm{~cm}$ dan G4 P4 memiliki panjang akar terendah dengan rerata $8,77 \mathrm{~cm}$. (Tabel 3). 
Tabel 1. Rerata Tinggi Tanaman Umur 42 HST Pada Perlakuan Beberapa Galur Kacang Bambara dan Taraf Penyiraman.

\begin{tabular}{|c|c|c|c|c|c|}
\hline \multirow{2}{*}{ Galur } & \multicolumn{4}{|c|}{ Penyiraman } & \multirow{2}{*}{ Rerata } \\
\hline & $\mathrm{P} 1$ & $\mathrm{P} 2$ & P3 & P4 & \\
\hline G1 & 6.28 & 5.07 & 6.10 & 5.10 & 5.64 \\
\hline $\mathrm{G} 2$ & 5.26 & 5.14 & 5.67 & 5.04 & 5.28 \\
\hline G3 & 5.30 & 4.68 & 5.47 & 5.20 & 5.16 \\
\hline G4 & 6.03 & 5.51 & 6.11 & 4.40 & 5.51 \\
\hline Rerata & $5.72 \mathrm{ab}$ & $5.1 \mathrm{ab}$ & $5.84 \mathrm{~b}$ & $4.94 \mathrm{a}$ & \\
\hline
\end{tabular}

Tabel 2. Rerata Jumlah Daun Umur 42 HST Pada Perlakuan Beberapa Galur Kacang Bambara dan Taraf Penyiraman.

\begin{tabular}{|c|c|c|c|c|c|}
\hline \multirow{2}{*}{ Galur } & \multicolumn{4}{|c|}{ Penyiraman } & \multirow{2}{*}{ Rerata } \\
\hline & P1 & $\mathrm{P} 2$ & $\mathrm{P} 3$ & P4 & \\
\hline G1 & 18.44 & 17.44 & 16.22 & 14.22 & 16.58 \\
\hline $\mathrm{G} 2$ & 19.67 & 17.44 & 16.00 & 14.56 & 16.92 \\
\hline G3 & 16.56 & 18.44 & 14.33 & 12.11 & 15.36 \\
\hline G4 & 18.44 & 17.89 & 17.00 & 12.00 & 16.33 \\
\hline & $18.28 \mathrm{c}$ & $17.81 \mathrm{bc}$ & $15.89 \mathrm{~b}$ & $13.22 \mathrm{a}$ & \\
\hline
\end{tabular}

Keterangan: Kolom dan baris yang mempunyai huruf yang sama menunjukkan tidak berbeda nyata berdasarkan uji BNJ 5\%.

Tabel 3. Rerata Panjang Akar Pada Perlakuan Beberapa Galur Kacang Bambara dan Taraf Penyiraman

\begin{tabular}{crrrrc}
\hline & \multicolumn{4}{c}{ Penyiraman } & \multicolumn{2}{c}{ Rerata } \\
\cline { 2 - 5 } Galur & P1 & \multicolumn{1}{c}{ P2 } & P3 & P4 \\
\hline G1 & $14.30 \mathrm{~h}$ & $13.56 \mathrm{fg}$ & $13.03 \mathrm{e}$ & $10.37 \mathrm{~b}$ & $12.81 \mathrm{~b}$ \\
G2 & $14.87 \mathrm{i}$ & $13.46 \mathrm{f}$ & $13.12 \mathrm{ef}$ & $10.44 \mathrm{~b}$ & $12.97 \mathrm{c}$ \\
G3 & $15.17 \mathrm{j}$ & $13.63 \mathrm{fg}$ & $12.94 \mathrm{e}$ & $10.34 \mathrm{~b}$ & $13.02 \mathrm{~d}$ \\
G4 & $13.86 \mathrm{~g}$ & $12.56 \mathrm{~d}$ & $12.21 \mathrm{c}$ & $8.77 \mathrm{a}$ & $11.85 \mathrm{a}$ \\
\hline Rerata & $14.55 \mathrm{~d}$ & $13.3 \mathrm{c}$ & $12.83 \mathrm{~b}$ & $9.98 \mathrm{a}$ &
\end{tabular}

Keterangan: Kolom dan baris yang mempunyai huruf yang sama menunjukkan tidak berbeda nyata berdasarkan uji BNJ $5 \%$.

\section{Karakter Hasil}

\section{Umur Berbunga}

Galur Madura 2 (G2) memiliki nilai tertinggi dengan rerata 101,25, sedangkan nilai rerata terendah terjadi pada Galur lokal Indonesia (G4) yaitu 76,44, taraf P1 yang memiliki rerata tertinggi yaitu 108,83 , sedangkan pada taraf P4 memiliki nilai rerata terendah yaitu 79,64. Interaksi G1P1, G2P1 dan G3P1 memiliki nilai rerata tertinggi dibandingkan interaksi lainnya. (Tabel 4).

\section{Jumlah Polong}

Galur lokal Indonesia (G4) memiliki nilai rerata tertinggi dibandingkan ketiga galur lainnya, G4 memberikan pengaruh nyata terhadap jumlah polong dengan rerata 2,94. Pada G1, G2 dan G3 menunjukkan nilai tidak berbeda nyata dengan diikuti notasi yang sama pada rerata jumlah polong tanaman bambara. Faktor penyiraman yang memberikan pengaruh nyata adalah faktor taraf P1 dengan rerata 4,42, sedangkan taraf $\mathrm{P} 4$ memiliki nilai rerata 0 , dimana taraf P4 tidak mampu menghasilkan polong pada tanaman kacang bambara. Interaksi terbaik terjadi pada G4P1 dengan rerata 6,22. (Tabel 5). 
Tabel 4. Rerata Umur Berbunga Pada Perlakuan Beberapa Galur Kacang Bambara dan Taraf Penyiraman

\begin{tabular}{|c|c|c|c|c|c|}
\hline \multirow{2}{*}{ Galur } & \multicolumn{4}{|c|}{ Penyiraman } & \multirow{2}{*}{ Rerata } \\
\hline & $\mathrm{P} 1$ & $\mathrm{P} 2$ & P3 & $\mathrm{P} 4$ & \\
\hline G1 & $115.00 \mathrm{~h}$ & $105.22 \mathrm{f}$ & $92.00 \mathrm{e}$ & $86.33 \mathrm{~d}$ & $\overline{99.64 \mathrm{c}}$ \\
\hline $\mathrm{G} 2$ & $114.89 \mathrm{~h}$ & $108.67 \mathrm{~g}$ & $93.89 \mathrm{e}$ & $87.56 \mathrm{~d}$ & $101.25 \mathrm{~d}$ \\
\hline G3 & $113.67 \mathrm{~h}$ & $106.44 \mathrm{fg}$ & $86.89 \mathrm{~d}$ & $83.56 \mathrm{~cd}$ & $97.64 \mathrm{~b}$ \\
\hline G4 & $91.78 \mathrm{e}$ & $81.33 \mathrm{c}$ & $71.56 \mathrm{~b}$ & $61.11 \mathrm{a}$ & $76.44 \mathrm{a}$ \\
\hline Rerata & $108.83 \mathrm{~d}$ & $100.42 \mathrm{c}$ & $86.08 \mathrm{~b}$ & $79.64 \mathrm{a}$ & \\
\hline
\end{tabular}

Keterangan: Kolom dan baris yang mempunyai huruf yang sama menunjukkan tidak berbeda nyata berdasarkan uji BNJ 5\%.

Tabel 5. Rerata Jumlah Polong Pada Perlakuan Beberapa Galur Kacang Bambara dan Taraf Penyiraman

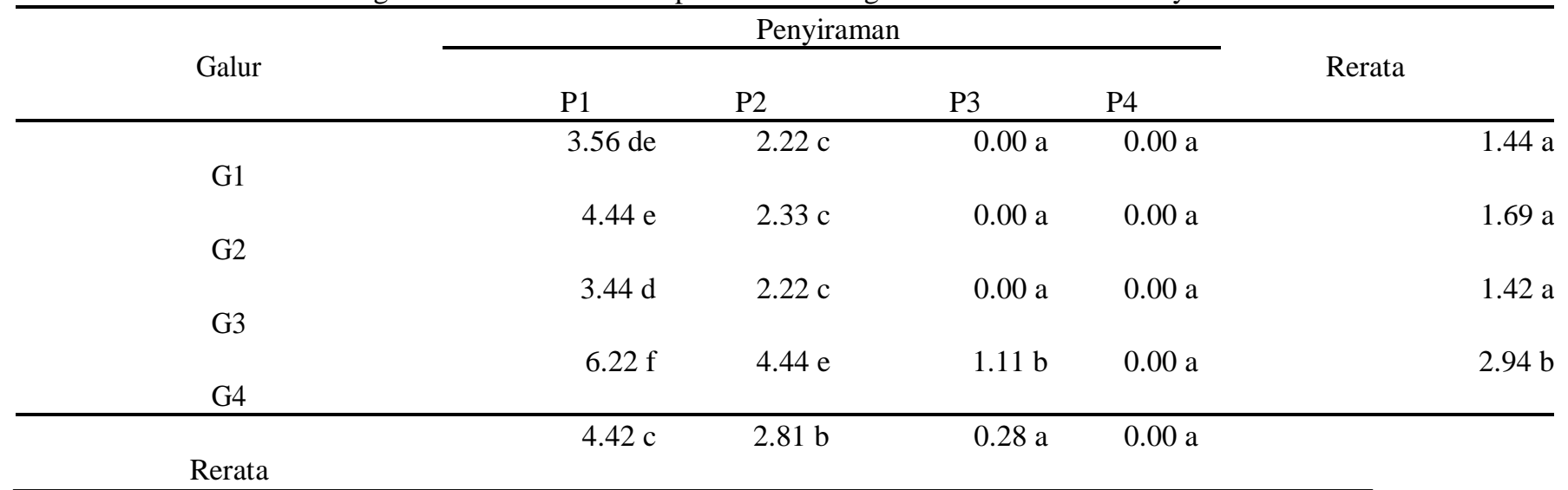

Keterangan: Kolom dan baris yang mempunyai huruf yang sama menunjukkan tidak berbeda nyata berdasarkan uji BNJ $5 \%$.

Tabel 6. Rerata Jumlah Biji Pertanaman Pada Perlakuan Beberapa Galur Kacang Bambara dan Taraf Penyiraman

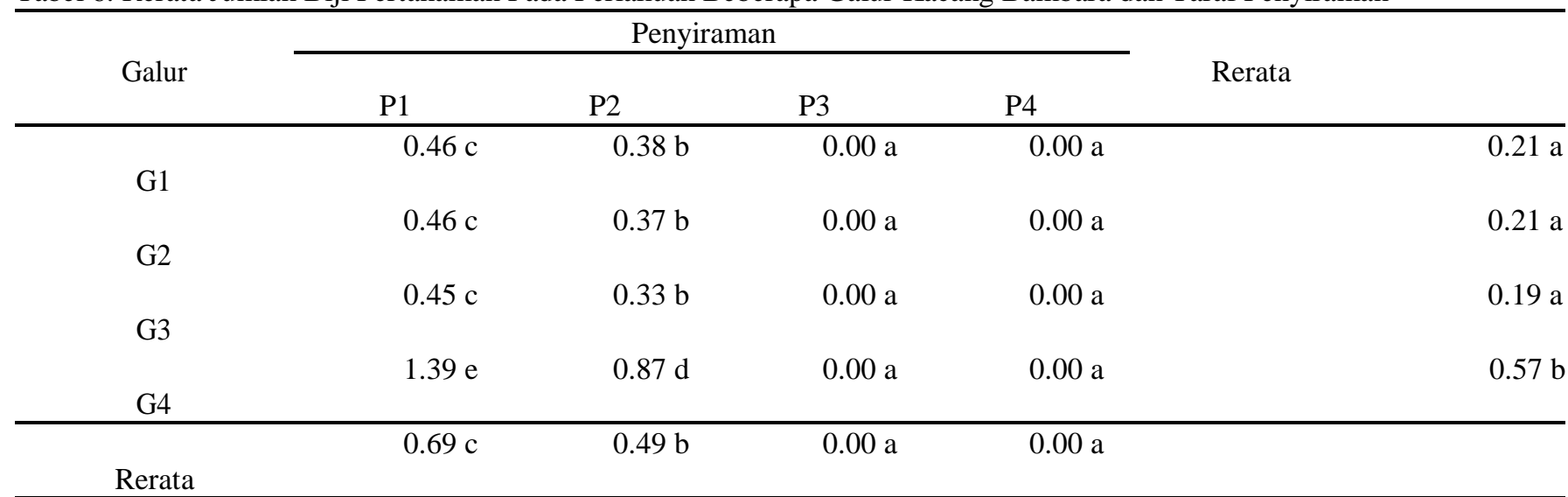

Keterangan: Kolom dan baris yang mempunyai huruf yang sama menunjukkan tidak berbeda nyata berdasarkan uji BNJ 5\%

\section{Jumlah Biji}

Galur lokal Indonesia (G4) memberikan nilai rerata tertinggi yaitu 0,57 , sedangkan G1, G2 dan G3 menunjukkan nilai tidak berbeda nyata terhadap jumlah polong yang ditunjukkan dengan notasi yang sama pada rerata ketiganya. Faktor taraf P1 memberikan pengaruh paling signifikan dengan rerata 0,69 , sedangkan faktor taraf P3 dan P4 memiliki rerata yang sama yaitu 0,00. Interaksi terbaik ditunjukkan oleh G4P1 dengan nilai rerata 1,39. (Tabel 6). 
Tabel 7. Rerata Berat Biji Pada Perlakuan beberapa galur Kacang Bambara dan Taraf Penyiraman (g)

\begin{tabular}{cccccc}
\hline \multirow{2}{*}{ Galur } & \multicolumn{4}{c}{ Penyiraman } & Rerata \\
\cline { 2 - 5 } & P1 & P2 & P3 & P4 & $1.03 \mathrm{a}$ \\
G1 & $2.22 \mathrm{c}$ & $1.89 \mathrm{~b}$ & $0.00 \mathrm{a}$ & $0.00 \mathrm{a}$ & $1.06 \mathrm{a}$ \\
$\mathrm{G} 2$ & $2.44 \mathrm{c}$ & $1.78 \mathrm{~b}$ & $0.00 \mathrm{a}$ & $0.00 \mathrm{a}$ & $0.97 \mathrm{a}$ \\
$\mathrm{G} 3$ & $2.22 \mathrm{c}$ & $1.67 \mathrm{~b}$ & $0.00 \mathrm{a}$ & $0.00 \mathrm{a}$ & $2.19 \mathrm{~b}$ \\
G4 & $4.78 \mathrm{e}$ & $4.00 \mathrm{~d}$ & $0.00 \mathrm{a}$ & $0.00 \mathrm{a}$ & \\
\hline Rerata & $2.92 \mathrm{c}$ & $2.33 \mathrm{~b}$ & $0.00 \mathrm{a}$ & $0.00 \mathrm{a}$ & \\
\hline
\end{tabular}

Keterangan: Kolom dan baris yang mempunyai huruf yang sama menunjukkan tidak berbeda nyata berdasarkan uji BNJ 5\%.

\section{Berat Biji}

Pada perlakuan galur G4 memberikan nilai tertinggi yaitu 2,19, sedangkan G1,G2 dan G3 tidak berbeda nyata dengan diikuti notasi yang sama. Perlakuan taraf penyiraman juga memberikan pengaruh signifikan terhadap jumlah biji yang dihasilkan. Taraf P1 memberikan rerata tertinggi yaitu 2,92 dan dilanjutkan taraf P2 yaitu 2,33, sedangkan perlakuan taraf P3 dan P4 menunjukkan nilai tidak berbeda nyata dengan rerata 0,00 . Kedua perlakuan tersebut terjadi interaksi, dimana interaksi terbaik dihasilkan pada G4P1 dengan rerata 4,78. (Tabel 7).

\section{Pembahasan}

Hasil analisis menunjukkan bahwa tanaman kacang bambara memperlihatkan respon yang berbeda-beda pada setiap taraf penyiraman sebagai perlakuan kekeringan. Setiap galur suatu tanaman memiliki perbedaan baik dalam pertumbuhannya maupun perkembangannya, sehingga perlakuan beberapa galur juga memberikan respon berbeda pada pertumbuhan kacang bambara. Kedua perlakuan tersebut memberikan pengaruh signifikan pada beberapa parameter pengamatan serta menunjukkan adanya interaksi perlakuan keduanya. Parameter pengamatan yang dilakukan adalah tinggi tanaman, jumlah daun, umur berbunga, akar terpanjang, jumlah polong, jumlah biji, dan berat biji pertanaman.

Taraf penyiraman yang tinggi mampu meningkatkan pertumbuhan tanaman dibandingkan taraf penyiraman yang rendah. Supriyanto (2013) mengemukakan bahwa Tanaman dengan kondisi air yang rendah dapat menghambat metabolisme seperti penyerapan nutrisi, menghambat pembelahan dan pembesaran sel, penurunan aktivitas enzim serta penutupan stomata sehingga pertumbuhan dan perkembangan tanaman menjadi terhambat. Pengaruh cekaman kekeringan tidak hanya menekan pertumbuhan dan hasil, namun menjadi penyebab kematian tanaman (Djazuli, 2010). Cekaman air dapat menyebabkan penurunan turgor tanaman, dimana tekanan turgor sangat berperan dalam menentukan ukuran tanaman, berpengaruh terhadap pembesaran dan perbanyakan sel tanaman (Nurhayati, 2009). Menurut Abdurrachman, et al (2005) mengemukakan bahwa air dalam tanah berperan sebagai pelarut dana agen pengikat antar partikel-partikel tanah, yang selanjutnya berpengaruh terhadap stabilitas struktur dan kekuatan tanah serta bahan geologik.

Galur tanaman kacang bambara memiliki karakter pertumbuhan yang berbeda. Tinggi tanaman menurun secara nyata dengan meningkatnya tingkat cekaman air. Daun kacang bambara merupakan tipe trifoliate. Menurut Nuryati (2014), jumlah daun tanaman kacang bambara berkembang secara eksponensial, yaitu jumlah daun selalu bertambah. Rendahnya ketersediaan air dalam tanah dapat mengakibatkan terhambatnya pembentukan daun baru, (Kurniasari, et al., 2010).

Mabhaudhi, et al (2011), semakin sedikit taraf penyiraman yang diberikan maka semakin cepat umur berbunga tanaman. Saat tanaman kekurangan air, maka tanaman akan mempercepat kelangsungan hidupnya. Parameter panjang akar dilakukan untuk mengetahui perkembangan akar tanaman pada kondisi jumlah air yang berbeda pada tanah sebagai tempat tumbuhnya. Farooq et al. (2009) menyebutkan bahwa salah satu mekanisme ketahanan kekeringan adalah dengan mengembangkan dan memperpanjang akar yang termasuk ke dalam mekanisme avoidance dimana tanaman meningkatkan penyerapan air dalam tanah dan mengurangi transpirasi dengan menutup stomata. Penurunan panjang akar dapat disebabkan oleh terganggunya perkembangan akar tanaman.

Redjeki (2007) mengemukakan bahwa kekerangan air saat post-flowering pada kacang bambara secara nyata menurunkan pertumbuhan, menurunkan jumlah polong. Panjang umur panen (4-5 bulan) pada tanaman kacang bambara serta musim hujan yang tidak pasti dapat mengakibatkan produksi reendah. Saat pengisian polong adalah saat kritis bagi tanaman kacang bambara. Kekurangan air dapat mengakibatkan polong menjadi sedikit, karena ginofor mengering sebelum terbentuk polong. 


\section{KESIMPULAN DAN SARAN}

\section{Kesimpulan}

Galur-galur kacang bambara yang diujikan tidak memberikan pengaruh pada parameter tinggi tanaman dan jumlah daun. Namun, galur-galur tersebut memberikan pengaruhpada parameter umur berbunga, panjang akar, jumlah polong, jumlah biji dan berat biji. Taraf penyiraman memberikan pengaruh pada setiap parameter pengamatan. Taraf P1 memberikan hasil terbaik pada setiap parameter pengamatan taraf P2 menunjukkan nilai tertinggi kedua setelah taraf P1, sedangkan pada taraf P3 dan P4 tanaman tidak dapat tumbuh optimal, dimana kedua taraf tersebut rata-rata tidak mampu menghasilkan polong kacang bambara. Interaksi terbaik ditunjukkan oleh G4P4 (Galur Lokal Indonesia dengan taraf penyiraman $100 \% \mathrm{KL}$ ). Kebutuhan air minimum yang direkomendasikan agar galur kacang bambara dapat tumbuh dengan baik adalah penyiraman taraf P2 $(174,9 \mathrm{ml})$ yaitu taraf penyiraman $75 \%$ KL.

\section{Saran}

1. Perlu dilakukan penelitian lanjutan terhadap galur kacang bambara yang lain untuk mendapatkan galur tahan terhadap kekeringan.

2. Perlu dilakukan penelitian frekuensi penyiraman galur kacang bambara untuk mengetahui tingkat ketahanan terhadap kekeringan.

\section{DAFTAR PUSTAKA}

Abdurachman, A., Umi Haryati, Ishak Juarsah. 2005. Penetapan kadar air tanah dengan metode gravimetrik. Balai Tanah Indonesia.

Djazuli, M. 2010. Pengaruh cekaman kekeringan terhadap pertumbuhan dan beberapa karakter morfo-fisiologis tanaman nilam. Bul. Littro. 21(1) : 8-17.

Farooq, M., A. Wahid, N. Kobayashi, D. Fujita, dan S. M. A. Basra. 2009. Plant Drought Stress : Effect, Mechanisms and Management. Agron. For Sustainable Development, Springeir Verlag (Germany). 29 (1) : pp. 185-212.

Harsono, A., Tohari, D. Indradewa dan T. Adisarwanto. 2003. Ketahanan dan Aktifitas Fisiologi Beberapa Genotip Kacang Tanah Pada Cekaman Kekeringan. Ilmu Pertanian 10 (2) : 51-62.

Hendrati, Rina L., Asri Insiana P., dan Dedi Setiadi. 2012. Seleksi spesies adaptif pada daerah kering untuk antisipasi perubahan iklim global. Balai Besar Penelitian Bioteknologi dan Pemuliaan Tanaman Hutan.
Jusuf, M. I. 2012. Ekologi Daerah Bencana Tsunami dengan Gangguan Kesehatan. J. Sainstek 6 (6) : 75-87

Kurniasari, A., M. Adisyahputra, Rosman. R. 2010. Pengaruh kekeringan pada tanah bergaram $\mathrm{NaCl}$ terhadap pertumbuhan tanaman nilam. Bul. Littro. 21(1) : 8-17.

Kuswanto, Waluyo B., Ranin Anindita P., dan Sartika C. 2003. Koleksi evaluasi galur-galur lokal Kacang Bambara (Vigna subterranean). Universitas Brawijaya.

Mabhaudhi, T., A. T. Modi., and Y. G. Beletse. 2011. Growth Responses of a Bambara Groundnut Landrace to Water Stress. African Crop Sci. Conference Proceeding. 10 : 97-102.

Nurhayati. 2009. Pengaruh cekamana air pada dua jenis tanah terhadap pertumbuhan dan hasil kedelai (Glycine max). J. Floratek $4: 5-64$.

Nuryati, Soegianto, A, Kuswanto. 2014. Genetic relationship and variability among Indonesian purfied local lines of bambara groundnut (Vigna subterranean) based on morphological character. African Journal of Science and Research, (3)5;18 24. ISSN: $2306-5877$

Prabawati, Dian. 2015. Evaluasi ketahanan beberapa galur bambara terhadap kekeringan. Universitas Brawijaya.

Redjeki, E. S. 2007. Pertumbuhan dan Hasil Tanaman Kacang Bogor (Vigna subterranean (L). Verd court ) Galur Gresik dan Bogor Pada Berbagai Warna Biji. UMG. ISBN: 978-979-15649-2-2.

Supriyanto, B. 2013. Pengaruh Cekaman Kekeringan Terhadap Pertumbuhan dan Hasil Padi Gogo Lokal Kultivar Jambu. J. AGRIFOR. 12 (1) : 77-82. 